\title{
Reclaiming Waste Rubber for a Green Environment
}

\author{
Sayed H. Kenawy 1,2 (D), Ahmed M. Khalil 3,* (D) \\ 1 Refractories, Ceramics and Building Materials Department, National Research Centre, El-Buhouth St., Dokki - 12622 , \\ Giza, Egypt \\ 2 Chemistry Department, College of Science, Imam Mohammad Ibn Saud Islamic University (IMSIU), Riyadh 11623, Saudi \\ Arabia \\ 3 Photochemistry Department, National Research Centre, El-Buhouth St., Dokki - 12622, Giza, Egypt \\ * Correspondence: akhali175@yahoo.com;
}

Scopus Author ID 55605778944

Received: 14.06.2020; Revised: 19.07.2020; Accepted: 20.07.2020; Published: 23.07.2020

\begin{abstract}
Waste rubber composes a burden on the environment. Consumed rubber does not degrade easily, and disposing of this waste is not a facile process. Worn out tire rubber forms a considerable section of the urban waste materials. It is able to be ground and known as ground tire rubber (GTR). It is favored to be devulcanized before being blended with organic or inorganic materials. (GTR) is able to constitute compatible blends or composites with polymers that possess appropriate mechanical, thermal, and morphological properties. Devulcanization process of waste rubber takes place by means of mechanical, mechano-chemical, or thermal treatment. Moreover, induced irradiation such as gamma or ultraviolet and accelerated electrons radiation(s) can assist in devulcanizing waste rubber by breaking the bonds which arose previously during the vulcanization process. Radiation is able to modify waste rubber by grafting its surface for an enhanced interfacial adhesion between it and the blended plastic or rubber. Loading GTR as a filler in composites contributes to lowering the cost of the resulting materials. In addition, modifying GTR can improve the performance of the composites in which they contribute. In this review, we aim to employ reclaimed waste rubber for a greener environment with better waste management procedures.
\end{abstract}

Keywords: Waste rubber; reclaiming; devulcanization; recycling; elastomer; surface treatment.

(C) 2020 by the authors. This article is an open-access article distributed under the terms and conditions of the Creative Commons Attribution (CC BY) license (https://creativecommons.org/licenses/by/4.0/).

\section{Introduction}

Rubber is a flexible class of polymers known as elastomers. It has the ability to expand and shrink. Rubber comprises natural and synthetic kinds. Natural rubber is produced as a latex. It is reaped as a sap from rubber trees. These trees are popular in Far East countries. Natural rubber is unable to cover the industrial needs across the world. Hence, it became a demand to find alternatives for natural rubber to supply various industries with these elastomeric materials. Synthetic rubbers include many kinds. Among these ones, we can mention styrenebutadiene rubber (SBR), ethylene propylene diene monomer (EPDM), silicone rubber (SiR), nitrile butadiene rubber (NBR) and neoprene. In addition, manufacturers contributed in enhancing the properties of synthetic rubber. This approach took place by adjusting and tailoring the produced rubber according to the required application [1-3]. Elastomers are capable of building up promising blends or composites with organic and inorganic compounds. These composites have tailored components that produce unique features. This process takes place by changing the amount of the loaded content for improving mechanical, antibacterial, and thermal behaviors of the prepared composites [4-7]. Researchers are able to control the 
resiliency and toughness of rubber. These elastomers exhibit various tensile strength, elongation and elasticity moduli. The physical, mechanical, and thermal properties have been enhanced. Rubber needs some additives to facilitate its processing and supports its performance upon being used. Some examples of the additives are stearic acid and zinc oxide. Although rubber is considered a major component of various industries, it represents an environmental burden upon being disposed of. Rubber does not decompose easily. It is one of the major municipal wastes. Crumb rubber resulting from waste tires can be mixed with cement [8-10]. Although this combination can be applied, it faces deterioration in the mechanical and morphological properties. This decrement can be correlated to the stiffness and poor interfacial adhesion with concrete. Scrap rubber as hydrophobic substrates has a propensity to drive out water from cement. This leads to weak bonding between crumb rubber and cement in the produced rubberized concrete. Scrap rubber can be retrieved from a vulcanized one to produce reclaimed rubber $[11,12]$. Reclaiming takes place as a recycling process through grinding consumed tires or treating them chemically. Hence, recycling or reclaiming can provide a solution for getting rid of consumed rubber. Reclaiming rubber is not a facile process to take place. This may be due to the crosslinking of rubber, which cannot be annihilated easily. Rubber has to be vulcanized to gain endurance in the tire industry. Vulcanization is known as an irreversible procedure to crosslink rubber. It takes place by using sulfur or its compounds. The waste tire rubber can be ground to produce powder, known as ground tire rubber (GTR) $[13,14]$. Mechanical properties of polymeric blends or composites are commonly degenerated upon being loaded with GTR. This feature results from an insufficient adhesion at the interface between GTR and the other polymer. Waste rubber is capable of being loaded as a filler into polymeric substrates. Fillers are added to polymers to be used for specific purposes. These targets include reducing the cost of these products by maintaining their thermal and mechanical properties. It is important for waste rubber to be devulcanized and treated before being used. The devulcanization process of waste rubber is carried out in the air. This will be accompanied by a partially oxidized surface of the rubber. Different functional groups will be generated to allow an easier interaction between the polymer and waste rubber particles.

It is necessary to reach the demanded magnitude of crosslinking with the lowest irradiation dose. This is to avert any oxidation that may arise at higher doses. Hence, the deterioration of physical or mechanical properties can be avoided. Some poly-functional monomers, known as co-agents [15-17] can be used to improve radiation crosslinking of polymers. Some co-agents, namely, N,N'-methylene bisacrylamide (MBAAm), and trimethylol propane trimethacrylate (TMPTMA) were used to cure rubber. These co-agents contributed to enhancing the physical, chemical, and mechanical properties of NBR with high-density polyethylene (HDPE) composites. They were reinforced with different loads of HAF carbon black [18]. These composites were treated with accelerated electrons. Upon employing triallylcyanurate, it exhibited progress in the physical, mechanical, and thermal properties of NBR/PVC blends. Poly-functional monomers (PFMs) as crosslinking co-agents on the radiation vulcanization of acrylonitrile rubber (NBR) upon being cured with electron beam irradiation [19]. The physical properties of NBR were enhanced by introducing low concentrations of (PFMs). The crosslinking density in the rubber was influenced by both the kind of (PFMs) and the acrylonitrile amount in NBR. Asphalt binders were investigated after being blended with waste ethylene propylene diene monomer rubber (EPDM) as a modifier. Various loads of EPDM were studied. The efficiency of bituminous mixtures with the modified binders of EPDM showed rational results for mechanical properties [20]. 
We aim in this review to focus on reclaiming waste rubber alongside with loading it into polymers after being treated. This is an attempt to elucidate possibilities to reduce some ecological problems towards living in a green environment.

\section{Reclaiming and devulcanizing waste rubber}

Reclaimed rubber can be blended with a virgin polymer to reduce the cost of the final product. Besides, it assists in lowering the environmental pollution. Devulcanization of rubber involves the cleavage of the present S-S and C-S bonds in the vulcanized rubber. This process is elucidated in Figure 1. The crosslinks have to split with maintaining the hydrocarbon chain structure [21,22]. Reusing waste polymers may include blending various consumed polymers.

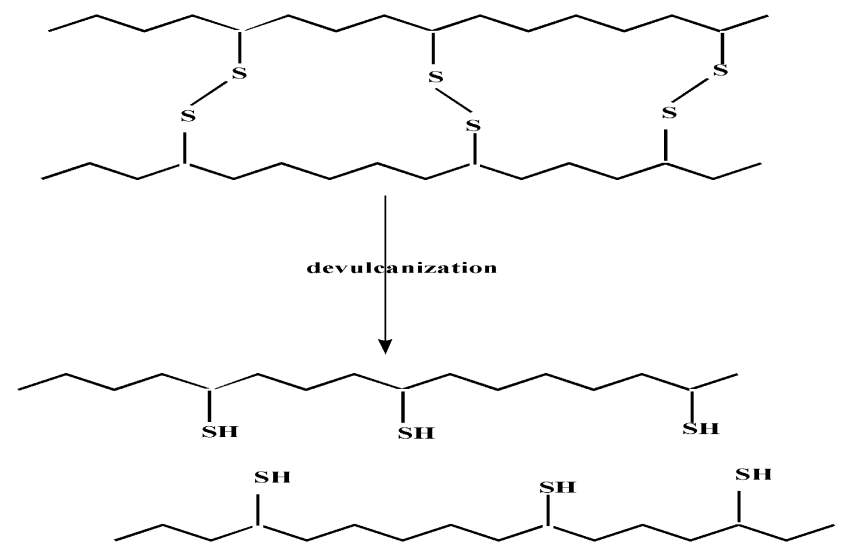

Figure 1. Schematic illustration for the devulcanization process of rubber.

GTR is able to be reclaimed and reused after being disposed of. This process needs modification via devulcanization, grafting, or radiation-induced treatment [23-25]. The surface GTR surface can compose polar groups such as hydroxy, peroxy, and carbonyl groups. The existence of these groups on GTR particles facilitates their interaction with polar polymers. Oxidation can take place by using $\mathrm{HNO}_{3}, \mathrm{H}_{2} \mathrm{SO}_{4}, \mathrm{KMnO}_{4}$, or $\mathrm{H}_{2} \mathrm{O}_{2}$ [26,27]. These materials etch the surface of GTR particles. Hence, a facile adhesion can occur between polymer and GTR. Induced radiation may be used to promote oxidation for the surface of GTR particles in the atmosphere. Gamma irradiation, ultraviolet, and electron beam accelerated radiation [2830]. Ethylene-vinyl acetate showed successful properties after being loaded with irradiated GTR particles. The mechanical properties of the blends were enhanced with augmenting the doses of electron beam radiation [31].

Reclaiming rubber takes place by the cleavage of $\mathrm{C}-\mathrm{C}$ bond in the rubber chain. At this stage, the molecular weight will diminish, and plasticity happens [32]. The breakdown of rubber chains occurs mainly on the surface extending inside the matrix with a relatively lower extent. Devulcanization is the scission of the carbon and sulfur bonds in the polymeric chains. Reclaiming and devulcanization of waste rubber may take place physically, chemically beside the bacterial treatment. The three-dimensional structure will collapse [21,33]. Upon reclamation and devulcanization processes, waste rubber is able to be reused in a close behavior to virgin one. Reclaimed rubber was found to be in the form of sol with slight crosslinked gel [34]. A thermal-oxidative treatment was used to reclaim ground tire rubber. This process was carried out by using a dynamic reclamation reactor. The proposed method showed a successful outcome for the thermal oxidation of GTR after 20 minutes at $200{ }^{\circ} \mathrm{C}$. The reclaimed GTR was 
used as a filler up to $40 \mathrm{wt} \%$ for natural rubber [35]. Crumb rubber particles were treated thermally at $200{ }^{\circ} \mathrm{C}$ before being mixed with concrete. The results of the treated rubberized concrete were improved upon comparison with the untreated concrete composites [36].

\section{Treating waste rubber with radiation}

Polymer blends are based on the kind of the components, either rubber or plastic. Recycling of waste rubbers is a significant case in encountering the environment. In the reclaiming process, it is important to detach three-dimensional crosslinks. Afterward, it will be easier to reprocess and vulcanize rubber [37,38]. Loading of ground rubber powder (GRP) as a filler for some polymers was investigated. GRP resulted from car and truck tires. They exhibited appropriate mechanical properties in the newly prepared polymeric composites [39]. The results showed a maintained level of mechanical properties without deterioration. This may be due to the reinforcement effect of carbon, which is present in the waste rubber powder [40]. Some researches were carried out to employ ground tire rubber (GTR) in preparing thermoplastic elastomeric blends. They comprised of virgin rubber, low-density polyethylene beside cured or uncured GTR [41]. The investigations exhibited acceptable properties for the tested blends. Reclaiming waste tire rubber is a serious environmental issue. Most of the recycled polymers exhibit deteriorated mechanical characteristics. Devulcanizing the crosslinked post-consumed rubber is a barrier to reuse waste rubber. Hence, unconventional devulcanization is proposed. Ionizing radiation shows some solutions for recycling polymers, mainly crosslinked rubber. Radiation is able to break the crosslinks of the polymeric chains. This process does not require to dissolve the waste polymers or any chemical treatment. Ground tire rubber (GTR) was utilized to prepare thermoplastic elastomers. These blends offer new applicable low-cost materials.

Gamma irradiation was used to devulcanize ground tire rubber (GTR). The reclaimed rubber was blended with high-density polyethylene to show enhanced mechanical features [42]. Introducing GTR as a filler for pristine natural rubber (NR) was surveyed [13,43]. Gamma rays were used to devulcanize loaded GTR in thermoplastic-elastomer blends. This was investigated in EPDM rubber blends with GTR [37]. There were enhancements in tensile strength, tear strength, and elongation at break. This may be correlated to the reinforcing effect of carbon in waste EPDM powder [44,45]. In EPDM/HDPE blends, the virgin rubber of EPDM was replaced with various contents of GTR [28]. This investigated blends containing waste rubber showed improved properties. Devulcanized rubber blends exhibit better mechanical properties than the vulcanized ones. Ultraviolet (UV) irradiation was applied for photografting. After grafting, the surface of rubber powder was modified and became able to act as filler for HDPE with maintaining the physical properties. Moreover, UV radiation was used to photo-crosslink EPDM. This process took place in the presence of benzil dimethyl ketal (BDK) and trimethylol propan triacrylate (TMPTA) as photoinitiator and crosslinker, respectively. The mechanical and morphological properties of crosslinked EPDM were influenced by various factors. They are irradiation time, concentrations of photoinitiator, and crosslinker besides the intensity of UV radiation [46]. EPDM was photo-crosslinked with polypropylene. The elastomer was subjected to UV rays in the presence of photoinitiator and crosslinker. It was concluded that the tensile properties boosted after being crosslinked. EPDM was compounded with GTR and high-density polyethylene (HDPE) in different proportions. The effect of radiation was monitored. The blends were submitted to gamma or UV radiation for 
comparison. Gamma radiation showed a more potent influence in enhancing the physical and mechanical properties of the investigated blends other than UV irradiation [28].

Many procedures [47-49] were suggested to present efficient methods for recycling consumed polymers. Ground tire rubber (GTR) was addressed to manufacture polymeric composites with practicable properties. These composites depend on the nature of the GTR, the kind of the polymer, GTR amount beside the adhesion between the polymer and GTR [26,50]. Ground tire rubber is a vulcanizate containing rubber and fillers. Many studies were carried out to compatibilized GTR particles with various polymeric substrates [51,52]. It was likely to blend recycled polyethylene with GTR by twin-screw extrusion. Reasonable mechanical properties were obtained at low GTR content by changing the process conditions. The latter conditions included screw rotation speed, temperature, and processing time. Enhancing the mechanical and dynamic mechanical properties of waste rubber powder with high-density polyethylene (HDPE) composite was followed up [30,53]. The surface of the rubber powder was progressed with acrylamide (AAm). It was irradiated by ultraviolet rays. This was pursued by extruding GTR and HDPE. Acrylamide grafted GTR showed an improvement in the mechanical properties of the surface-treated rubber/HDPE composite other than the untreated one.

\section{Incorporating rubber with polymeric wastes}

Various polymeric wastes can be used mixed with rubber (either virgin or waste) to obtain products with better properties. It is not mandatory to obtain enhanced characteristics for the originated materials. Monitoring the behavior of these substrates without deterioration is reasonable to have low cost recycled materials. Among these wastes, we can mention the resulting wastes from plastics and cellulosic materials. Wastes of some cellulosic substrates are able to be used as fillers in polymeric composites. These fillers are valid at low prices. Besides, they are eco-friendly materials $[54,55]$. They can be amended chemically to compatibilized upon being introduced to rubber. This modification increases the adhesion between the rubber and the cellulosic filler. Olive husk was ground to produce a powder. The latter powder was treated chemically. The modification enhanced its dispersion in carboxylated nitrile butadiene rubber with improving the mechanical properties [56]. Ground tire rubber was reclaimed through gamma or microwave devulcanization [37,57]. Virgin rubber is able to be substituted partially with the reclaimed one [58]. Waste rubber was blended with acrylonitrile butadiene rubber (NBR). These composites were crosslinked after being irradiated by gamma doses up to $250 \mathrm{kGy}$. Mechanical properties were improved proportionally with increasing the irradiation doses. Furthermore, polymer composites based on NBR and waste rubber were prepared. These composites were loaded with various contents of olive stones waste. The latter cellulosic waste was modified with acrylate monomer for obtaining a more efficient surface. Noticeable improvements were gained after this treatment, mainly in thermal properties and the ability to absorb water [59]. Waste crosslinked polyethylene was blended mechanochemically with GTR [60]. It was not easy for waste polyethylene to melt smoothly as a thermoplastic polymer. GTR was devulcanized partially as denoted through the carried out investigations. Recycled high-density polyethylene was blended with GTR [42]. The results demonstrated a degeneration in the tensile and impact properties upon raising the loading of GTR. Investigating polypropylene and ground tire rubber blends showed the same behavior [61]. The mechanical properties declined at high GTR concentrations. Hence, surface 
modification of waste rubber was recommended to obtain better results with enhanced properties for the tested blends that contain waste rubber contents.

Used polystyrene is present as a waste polymer. Expanded polystyrene (EPS) is among the common plastic wastes. It has a low density and can be employed in different applications [62-64]. It is a chemically resistant thermal insulator at a reduced cost. EPS was mixed with cement to compose light thermal insulating composites [65-68]. Induced radiation may assist in improving the compatibility upon blending the polymeric components. Some interactions arise to enhance the interfacial adhesion between the ingredients [69,70]. Waste rubber (WR) was devulcanized, then blended as devulcanized waste tire rubber (DWR) with EPS mechanically is shown in Figure 2. The produced thermoplastic elastomers showed acceptable mechanical, thermal, and morphological properties [71].

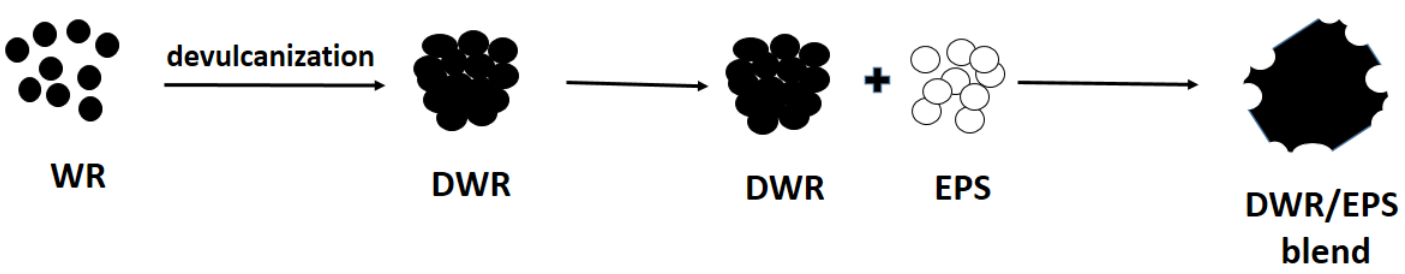

Figure 2. Blending waste rubber with expanded polystyrene.

Short fiber polymer composites possess the advantages of being elastic and stiff. These features have been gained from the rubber and fiber contents, respectively. Some studies were developed to enhance the mechanical properties of fiber-reinforced composites [72-74]. The adhesion and bonding between rubber and fiber are influenced by the structure of these polymeric components [75-77]. Polyethylene terephthalate (PET) can form efficient fibers. They show good mechanical properties, mainly high modulus with minimum retraction. However, a disadvantage may arise as a result of poor adhesion between PET and rubber. Some chemicals such as hydrated silica and hexamethylenetetramine (HMT) can be used to overcome this drawback. Such modification was studied to adhere to PET fibers with Styrene-butadiene rubber. The results showed a progressive adhesion with good morphology and mechanical properties [78]. Ethylene-propylene diene rubber (EPDM) was loaded with waste PET fibers to produce reinforced composites. Electron beam irradiation was used for vulcanizing these enhanced composites. Several irradiation doses were utilized in the range of 25-150 kGy [79]. Scanning electron microscopy displayed good adhesion between EPDM and waste PET fibers. Natural rubber was blended with cellulose nanowhiskers. These whiskers were released from waste bamboo pulp [80]. Introducing the nanowhiskers to the prepared nanocomposites enhanced their mechanical and thermal performances. The laminate method was used to prepare composites based on natural rubber glove waste and polystyrene foam in the presence of cellulose from sugar cane [81]. The hardness of the composites increased upon raising the polystyrene content. Meanwhile, the impact strength boosted at higher loadings of natural rubber and waste cellulose.

\section{Conclusions}

Rubber is a major category of polymers. It is present as either natural or synthetic rubber. Disposing of consumed rubber is a complicated process. It does not degrade and cannot be recycled easily. This is due to its vulcanized form that makes it endure and last for a long time interval upon being utilized. It is favored to reclaim and devulcanize waste rubber to be 
able to be reused. Devulcanization takes place through splitting carbon-sulfur, and sulfur-sulfur bonds in the polymeric chains of rubber, blending of reclaimed waste rubber after being ground as particles facilitate its dispersion inside rubber and thermoplastic structures. Using waste rubber in polymer composites is restricted. This results from the poor adhesion between the polymer and the vulcanized waste rubber. Hence, devulcanization of waste rubber or surface treatment can be recommended for superior interfacial adhesion between the treated waste rubber and the blended rubber or plastic. Consequently, enhanced performance for the polymeric blends or composites loaded with treated waste rubber can be observed. Induced irradiation by means of ultraviolet or gamma rays, in addition to accelerated electron beam radiation, has a serious role in devulcanizing and/or improving the surface of waste rubber.

\section{Funding}

This research received no external funding.

\section{Acknowledgments}

This research has no acknowledgment.

\section{Conflicts of Interest}

The authors declare no conflict of interest.

\section{References}

1. Hernandez, M.; Grande, A.M.; Dierkes, W.; Bijleveld, J.; Van Der Zwaag, S.; Garcia, S.J. Turning vulcanized natural rubber into a self-healing polymer: effect of the disulfide/polysulfide ratio. ACS Sustainable Chemistry \& Engineering 2016, 4, 5776-5784, https://doi.org/10.1021/acssuschemeng.6b01760.

2. Pashaei, S.; Hosseinzadeh, S.; Syed, A.A. Studies on coconut shell powder and crysnanoclay incorporated acrylonitrile-butadiene rubber/styrene butadiene rubber (NBR/SBR) green nanocomposites. Polymer Composites 2017, 38, 727-735, https://doi.org/10.1002/pc.23632.

3. Zhou, H.; Wang, H.; Niu, H.; Gestos, A.; Wang, X.; Lin, T. Fluoroalkyl silane modified silicone rubber/nanoparticle composite: a super durable, robust superhydrophobic fabric coating. Advanced materials 2012, 24, 2409-2412, https://doi.org/10.1002/adma.201200184.

4. Shojaei, A.; Faghihi, M. Physico-mechanical properties and thermal stability of thermoset nanocomposites based on styrene-butadiene rubber/phenolic resin blend. Materials Science and Engineering: A 2010, 527, 917-926, https://doi.org/10.1016/j.msea.2009.10.022.

5. Mangili, I.; Lasagni, M.; Anzano, M.; Collina, E.; Tatangelo, V.; Franzetti, A.; Caracino, P.; Isayev, A.I. Mechanical and rheological properties of natural rubber compounds containing devulcanized ground tire rubber from several methods. Polymer Degradation and Stability 2015, 121, 369-377, https://doi.org/10.1016/j.polymdegradstab.2015.10.004.

6. Bhawal, P.; Das, T.K.; Ganguly, S.; Mondal, S.; Das, N.C. Selective crosslinking of carboxylated acrylonitrile butadiene rubber and study of their technological compatibility with poly (ethylene-co-methyl acrlylate) by means of mechanical, thermal, and chemical analysis. Polymer Bulletin 2019, 76, 1877-1897, https://doi.org/10.1007/s00289-018-2474-z.

7. Khalil, A.M.; Rabie, S.T. Mechanical, thermal and antibacterial performances of acrylonitrile butadiene rubber/polyvinyl chloride loaded with Moringa oleifera leaves powder. Journal of Thermal Analysis and Calorimetry 2019, https://doi.org/10.1007/s10973-019-09194-5.

8. He, L.; Ma, Y.; Liu, Q.; Mu, Y. Surface modification of crumb rubber and its influence on the mechanical properties of rubber-cement concrete. Construction and Building Materials 2016, 120, 403-407, https://doi.org/10.1016/j.conbuildmat.2016.05.025.

9. Adeboje, A.O.; Kupolati, W.K.; Sadiku, E.R.; Ndambuki, J.M.; Kambole, C. Experimental investigation of modified bentonite clay-crumb rubber concrete. Construction and Building Materials 2020, 233, https://doi.org/10.1016/j.conbuildmat.2019.117187.

10. Chen, Z.; Li, L.; Xiong, Z. Investigation on the interfacial behaviour between the rubber-cement matrix of the rubberized concrete. Journal of cleaner production 2019, 209, 1354-1364, https://doi.org/10.1016/j.jclepro.2018.10.305. 
11. Gauthier-Maradei, P.; Ruiz, C.P.T.; Capron, M. Oil and Aromatic Yield Maximization During Pyrolysis of Scrap Tire Rubber. Waste and Biomass Valorization 2019, 10, 3723-3733, https://doi.org/10.1007/s12649019-00695-w.

12. Dubkov, K.A.; Semikolenov, S.V.; Ivanov, D.P.; Babushkin, D.E.; Voronchikhin, V.D. Scrap tyre rubber depolymerization by nitrous oxide: products and mechanism of reaction. Iranian Polymer Journal 2014, 23, 881-890, https://doi.org/10.1007/s13726-014-0284-1.

13. Zhang, X.; Lu, C.; Liang, M. Properties of natural rubber vulcanizates containing mechanochemically devulcanized ground tire rubber. Journal of Polymer Research 2009, 16, 411-419, https://doi.org/10.1007/s10965-008-9243-x.

14. Stelescu, M.D.; Manaila, E.; Craciun, G.; Zuga, N. Crosslinking and grafting ethylene vinyl acetate copolymer with accelerated electrons in the presence of poly-functional monomers. Polymer Bulletin 2012, 68, 263-285, https://doi.org/10.1007/s00289-011-0629-2.

15. Jinhua, W.; Yoshii, F.; Makuuchi, K. Radiation vulcanization of ethylene-propylene rubber with polyfunctional monomers. Radiation Physics and Chemistry 2001, 60, 139-142, https://doi.org/10.1016/S0969806X(00)00306-6.

16. Ahmed, J.; Wu, J.; Mushtaq, S.; Zhang, Y. Effects of electron beam irradiation and multi-functional monomer/co-agents on the mechanical and thermal properties of ethylene-vinyl acetate copolymer/polyamide blends. Materials Today Communications 2020, 23, https://doi.org/10.1016/j.mtcomm.2019.100840.

17. Yasin, T.; Khan, S.; Shafiq, M.; Gill, R. Radiation crosslinking of styrene-butadiene rubber containing waste tire rubber and poly-functional monomers. Radiation Physics and Chemistry 2015, 106, 343-347, https://doi.org/10.1016/j.radphyschem.2014.08.017.

18. Abou Zeid, M.M.; Shaltout, N.A.; Khalil, A.M.; El Miligy, A.A. Effect of different co-agents on physicochemical properties of electron beam cured NBR/HDPE composites reinforced with HAF carbon black. Polymer Composites 2008, 29, 1321-1327, https://doi.org/10.1002/pc.20515.

19. Yasin, T.; Ahmed, S.; Yoshii, F.; Makuuchi, K. Effect of acrylonitrile content on physical properties of electron beam irradiated acrylonitrile-butadiene rubber. Reactive and Functional Polymers 2003, 57, 113118, https://doi.org/10.1016/j.reactfunctpolym.2003.08.004.

20. Kumar, A.; Choudhary, R.; Kumar, A. Characterisation of asphalt binder modified with ethylene-propylenediene-monomer (EPDM) rubber waste from automobile industry. Road Materials and Pavement Design 2020, 1-25, https://doi.org/10.1080/14680629.2020.1740772.

21. Asaro, L.; Gratton, M.; Seghar, S.; Hocine, N.A. Recycling of rubber wastes by devulcanization. Resources. Conservation and Recycling 2018, 133, 250-262, https://doi.org/10.1016/j.resconrec.2018.02.016.

22. Aoudia, K.; Azem, S.; Hocine, N.A.; Gratton, M.; Pettarin, V.; Seghar, S. Recycling of waste tire rubber: Microwave devulcanization and incorporation in a thermoset resin. Waste Management 2017, 60, 471-481, https://doi.org/10.1016/j.wasman.2016.10.051.

23. Zedler, L.; Colom, X.; Canavate, J.; Saeb, M.R.; Haponiuk, J.; Formela, K. Investigating the impact of curing system on structure-property relationship of natural rubber modified with brewery by-product and ground tire rubber. Polymers 2020, 12, https://doi.org/10.3390/polym12030545.

24. de Sousa, F.D.; Zanchet, A.; Scuracchio, C.H. From devulcanization to revulcanization: Challenges in getting recycled tire rubber for technical applications. ACS Sustainable Chemistry \& Engineering 2019, 7, 8755-8765, https://doi.org/10.1021/acssuschemeng.9b00655.

25. Song, P.; Zhao, X.; Cheng, X.; Li, S.; Wang, S. Recycling the nanostructured carbon from waste tires. Composites Communications 2018, 7, 12-15, https://doi.org/10.1016/j.coco.2017.12.001.

26. Sonnier, R.; Leroy, E.; Clerc, L.; Bergeret, A.; Lopez-Cuesta, J.M. Polyethylene/ground tyre rubber blends: Influence of particle morphology and oxidation on mechanical properties. Polymer Testing 2007, 26, 274281, https://doi.org/10.1016/j.polymertesting.2006.10.011.

27. Karger-Kocsis, J.; Meszaros, L.; Barany, T. Ground tyre rubber (GTR) in thermoplastics, thermosets, and rubbers. Journal of Materials Science 2013, 48, 1-38, https://doi.org/10.1007/s10853-012-6564-2.

28. Zeid, M.A.; Rabie, S.T.; Nada, A.A.; Khalil, A.M.; Hilal, R.H. Effect of gamma and UV radiation on properties of EPDM/GTR/HDPE blends. Polymer-Plastics Technology and Engineering 2008, 47, 567-575, https://doi.org/10.1080/03602550801949496.

29. Meszaros, L.; Barany, T.; Czvikovszky, T. EB-promoted recycling of waste tire rubber with polyolefins. Radiation Physics and Chemistry 2012, 81, 1357-1360, https://doi.org/10.1016/j.radphyschem.2011.11.058.

30. El-Nemr, K.F.; Khalil, A.M. Gamma irradiation of treated waste rubber powder and its composites with waste polyethylene. Journal of Vinyl and Additive Technology 2011, 17, 58-63, https://doi.org/10.1002/vnl.20245.

31. Ramarad, S.; Ratnam, C.T.; Khalid, M.; Chuah, A.L.; Hanson, S. Improved crystallinity and dynamic mechanical properties of reclaimed waste tire rubber/EVA blends under the influence of electron beam irradiation. Radiation Physics and Chemistry 2017, 130, 362-370, https://doi.org/10.1016/j.radphyschem.2016.09.023. 
32. De, D.; Das, A.; De, D.; Dey, B.; Debnath, S.C.; Roy, B.C. Reclaiming of ground rubber tire (GRT) by a novel reclaiming agent. European Polymer Journal 2006, 42, 917-927, https://doi.org/10.1016/j.eurpolymj.2005.10.003.

33. Myhre, M.; Saiwari, S.; Dierkes, W.; Noordermeer, J. Rubber recycling: chemistry, processing, and applications. Rubber Chemistry and Technology 2012, 85, 408-449, https://doi.org/10.5254/rct.12.87973.

34. Shi, J.; Jiang, K.; Ren, D.; Zou, H.; Wang, Y.; Lv, X.; Zhang, L. Structure and performance of reclaimed rubber obtained by different methods. Journal of Applied Polymer Science 2013, 129, 999-1007, https://doi.org/10.1002/app.38727.

35. Zhang, Y.; Zhang, Z.; Wemyss, A.M.; Wan, C.; Liu, Y.; Song, P.; Wang, S. Effective thermal-oxidative reclamation of waste tire rubbers for producing high-performance rubber composites. ACS Sustainable Chemistry \& Engineering 2020, 8, 9079-9087, https://doi.org/10.1021/acssuschemeng.0c02292.

36. Abd-Elaal, E.S.; Araby, S.; Mills, J.E.; Youssf, O.; Roychand, R.; Ma, X.; Zhuge, Y.; Gravina, R.J. Novel approach to improve crumb rubber concrete strength using thermal treatment. Construction and Building Materials 2019, 229, https://doi.org/10.1016/j.conbuildmat.2019.116901.

37. Zeid, M.A.; Rabie, S.T.; Nada, A.A.; Khalil, A.M.; Hilal, R.H. Effect of gamma irradiation on ethylene propylene diene terpolymer rubber composites. Nuclear Instruments and Methods in Physics Research Section B: Beam Interactions with Materials and Atoms 2008, 266, 111-116, https://doi.org/10.1016/j.nimb.2007.10.037.

38. Zhang, X.; Saha, P.; Cao, L.; Li, H.; Kim, J. Devulcanization of waste rubber powder using thiobisphenols as novel reclaiming agent. Waste Management 2018, 78, 980-991, https://doi.org/10.1016/j.wasman.2018.07.016.

39. Li, S.; Lamminmaki, J.; Hanhi, K. Improvement of mechanical properties of rubber compounds using waste rubber/virgin rubber. Polymer Engineering \& Science 2005, 45, 1239-1246, https://doi.org/10.1002/pen.20402.

40. Nabil, H.; Ismail, H.; Azura, A.R. Compounding, mechanical and morphological properties of carbon-blackfilled natural rubber/recycled ethylene-propylene-diene-monomer (NR/R-EPDM) blends. Polymer Testing 2013, 32, 385-393, https://doi.org/10.1016/j.polymertesting.2012.11.003.

41. Kumar, C.R.; Fuhrmann, I.; Karger-Kocsis, J. LDPE-based thermoplastic elastomers containing ground tire rubber with and without dynamic curing. Polymer Degradation and Stability 2002, 76, 137-144, https://doi.org/10.1016/S0141-3910(02)00007-1.

42. Sonnier, R.; Leroy, E.; Clerc, L.; Bergeret, A.; Lopez-Cuesta, J.M. Compatibilisation of polyethylene/ground tyre rubber blends by $\gamma$ irradiation. Polymer Degradation and Stability 2006, 91, 2375-2379, https://doi.org/10.1016/j.polymdegradstab.2006.04.001.

43. Yehia, A.A.; Mull, M.A.; Ismail, M.N.; Hefny, Y.A.; Abdel-Bary, E.M. Effect of chemically modified waste rubber powder as a filler in natural rubber vulcanizates. Journal of Applied Polymer Science 2004, 93, 3036, https://doi.org/10.1002/app.20349.

44. Sutanto, P.; Picchioni, F.; Janssen, L.P.B.M.; Dijkhuis, K.A.J.; Dierkes, W.K.; Noordermeer, J.W. EPDM rubber reclaim from devulcanized EPDM. Journal of Applied Polymer Science 2006, 102, 5948-5957, https://doi.org/10.1002/app.25153.

45. Jacob, C.; De, P.P.; Bhowmick, A.K.; De, S.K. Recycling of EPDM waste. I. Effect of ground EPDM vulcanizate on properties of EPDM rubber. Journal of Applied Polymer Science 2001, 82, 3293-3303, https://doi.org/10.1002/app.2188.

46. Saleh, T.A.; Gupta, V.K. Processing methods, characteristics and adsorption behavior of tire derived carbons: a review. Advances in Colloid and Interface Science 2014, 211, 93-101, https://doi.org/10.1016/j.cis.2014.06.006.

47. Rattanasom, N.; Poonsuk, A.; Makmoon, T. Effect of curing system on the mechanical properties and heat aging resistance of natural rubber/tire tread reclaimed rubber blends. Polymer Testing 2005, 24, 728-732, https://doi.org/10.1016/j.polymertesting.2005.04.008.

48. Zanchet, A.; Masiero, A.; de Sousa, F.D.B.; Brandalise, R.N. The influence of UV-accelerated aging process on industrial waste containing EPDM. Recycling 2019, 4, https://doi.org/10.3390/recycling4020025.

49. Ramarad, S.; Khalid, M.; Ratnam, C.T.; Chuah, A.L.; Rashmi, W. Waste tire rubber in polymer blends: A review on the evolution, properties and future. Progress in Materials Science 2015, 72, 100-140, https://doi.org/10.1016/j.pmatsci.2015.02.004.

50. Sripornsawat, B.; Saiwari, S.; Nakason, C. Thermoplastic vulcanizates based on waste truck tire rubber and copolyester blends reinforced with carbon black. Waste Management 2018, 79, 638-646, https://doi.org/10.1016/j.wasman.2018.08.038.

51. Zhang, X.; Zhu, X.; Liang, M.; Lu, C. Improvement of the properties of ground tire rubber (GTR)-filled nitrile rubber vulcanizates through plasma surface modification of GTR powder. Journal of Applied Polymer Science 2009, 114, 1118-1125, https://doi.org/10.1002/app.30626.

52. Wu, B.; Zhou, M.H., Recycling of waste tyre rubber into oil absorbent. Waste Management 2009, 29, 355359, https://doi.org/10.1016/j.wasman.2008.03.002. 
53. Kim, J.I.; Ryu, S.H.; Chang, Y.W. Mechanical and dynamic mechanical properties of waste rubber powder/HDPE composite. Journal of Applied Polymer Science 2000, 77, 2595-2602, https://doi.org/10.1002/1097-4628(20000919)77:12<2595::AID-APP60>3.0.CO;2-C.

54. Shaghaleh, H.; Xu, X.; Wang, S. Current progress in production of biopolymeric materials based on cellulose, cellulose nanofibers, and cellulose derivatives. RSC Advances 2018, 8, 825-842, https://doi.org/10.1039/C7RA11157F.

55. Wu, Y.; Xia, C.; Cai, L.; Garcia, A.C.; Shi, S.Q. Development of natural fiber-reinforced composite with comparable mechanical properties and reduced energy consumption and environmental impacts for replacing automotive glass-fiber sheet molding compound. Journal of Cleaner Production 2018, 184, 92-100, https://doi.org/10.1016/j.jclepro.2018.02.257.

56. Mousa, A.; Heinrich, G.; Wagenknecht, U. Rubber-wood composites from chemically modified olive husk powder and carboxylated nitrile butadiene rubber: cure characteristics, tensile behavior, and morphological studies. Journal of Wood Chemistry and Technology 2012, 32, 82-92, https://doi.org/10.1080/02773813.2011.599469.

57. Diaz, R.; Colomines, G.; Peuvrel-Disdier, E.; Deterre, R. Thermo-mechanical recycling of rubber: Relationship between material properties and specific mechanical energy. Journal of Materials Processing Technology 2018, 252, 454-468, https://doi.org/10.1016/j.jmatprotec.2017.10.014.

58. Lonca, G.; Muggeo, R.; Imbeault-Tetreault, H.; Bernard, S.; Margni, M. Does material circularity rhyme with environmental efficiency? Case studies on used tires. Journal of Cleaner Production 2018, 183, 424435, https://doi.org/10.1016/j.jclepro.2018.02.108.

59. Khalil, A.M.; El-Nemr, K.F.; Hassan, M.L. Acrylate-modified gamma-irradiated olive stones waste as a filler for acrylonitrile butadiene rubber/devulcanized rubber composites. Journal of Polymer Research 2019, 26, 249, https://doi.org/10.1007/s10965-019-1914-2.

60. Zhang, X.; Lu, C.; Liang, M. Preparation of thermoplastic vulcanizates based on waste crosslinked polyethylene and ground tire rubber through dynamic vulcanization. Journal of Applied Polymer Science 2011, 122, 2110-2120, https://doi.org/10.1002/app.34293.

61. Ismail, H.; Awang, M.; Hazizan, M.A. Effect of waste tire dust (WTD) size on the mechanical and morphological properties of polypropylene/waste tire dust (PP/WTD) blends. Polymer-Plastics Technology and Engineering 2006, 45, 463-468. https://doi.org/10.1080/03602550600553739.

62. Dixit, A.; Dai Pang, S.; Kang, S.H.; Moon, J. Lightweight structural cement composites with expanded polystyrene (EPS) for enhanced thermal insulation. Cement and Concrete Composites 2019, 102, 185-197, https://doi.org/10.1016/j.cemconcomp.2019.04.023.

63. Sekharan, R.V.; Abraham, B.T.; Thachil, E.T. Utilization of waste expanded polystyrene: Blends with silicafilled natural rubber. Materials \& Design 2012, 40, 221-228, https://doi.org/10.1016/j.matdes.2012.03.042.

64. Khalil, A.M.; Kenawy, S.H. Hybrid Membranes Based on Clay-Polymer for Removing Methylene Blue from Water. Acta Chimica Slovenica 2020, 67, 96-104, http://dx.doi.org/10.17344/acsi.2019.5227.

65. Ayse, K.; Filiz, K.A.R. Properties of concrete containing waste expanded polystyrene and natural resin. $\begin{array}{lllll}\text { Construction } \quad \text { and } & \text { Building } & \text { 2016, } & \text { 105, } & \text { 572-578, }\end{array}$ https://doi.org/10.1016/j.conbuildmat.2015.12.177.

66. Lu, W.; Miao, L.; Zhang, J.; Zhang, Y.; Li, J., Characteristics of deformation and damping of cement treated and expanded polystyrene mixed lightweight subgrade fill under cyclic load. Applied Sciences 2019, 9, https://doi.org/10.3390/app9010167.

67. Solomon, A.A.; Hemalatha, G. Characteristics of expanded polystyrene (EPS) and its impact on mechanical and thermal performance of insulated concrete form (ICF) system. Structures 2020, 23, 204-213, https://doi.org/10.1016/j.istruc.2019.10.019.

68. Lee, J.H.; Kang, S.H.; Ha, Y.J.; Hong, S.G. 2018. Structural behavior of durable composite sandwich panels with high performance expanded polystyrene concrete. International Journal of Concrete Structures and Materials 2018, 12, https://doi.org/10.1186/s40069-018-0255-6.

69. Martinez-Lopez, M.; Martinez-Barrera, G.; Barrera-Diaz, C.; Urena-Nunez, F.; Dos Reis, J.M.L. Waste Tetra Pak particles from beverage containers as reinforcements in polymer mortar: Effect of gamma irradiation as an interfacial coupling factor. Construction and Building Materials 2016, 121, 1-8, https://doi.org/10.1016/j.conbuildmat.2016.05.153.

70. Xu, C.; Liu, J.; Zhu, X.; Zhu, Y.; Xiong, X.; Cheng, X. Electromagnetic interference shielding boards produced using Tetra Paks waste and iron fiber. Journal of Material Cycles and Waste Management 2015, 17, 391-398, https://doi.org/10.1007/s10163-014-0255-9.

71. El-Nemr, K.F.; Khalil, A.M.; Fathy, E.S. Thermoplastic elastomers based on waste rubber and expanded polystyrene: Role of devulcanization and ionizing radiation. International Journal of Polymer Analysis and Characterization 2018, 23, 58-69, https://doi.org/10.1080/1023666X.2017.1387447.

72. Martins, M.A.; Mattoso, L.H.C. Short sisal fiber-reinforced tire rubber composites: Dynamic and mechanical properties. Journal of Applied Polymer Science 2004, 91, 670-677, https://doi.org/10.1002/app.13210.

73. Pesetskii, S.S.; Shevchenko, V.V.; Dubrovsky, V.V. Morphology and properties of poly (ethylene terephthalate) and thermoplastic polyester elastomer blends modified in the melt by a diisocyanate chain 
extender and filled with a short glass fiber. Journal of Applied Polymer Science 2018, 135, https://doi.org/10.1002/app.45711.

74. Ahmad, M.A.A.; Majid, M.A.; Ridzuan, M.J.M.; Mazlee, M.N.; Gibson, A.G., Dynamic mechanical analysis and effects of moisture on mechanical properties of interwoven hemp/polyethylene terephthalate (PET) hybrid composites. Construction and Building Materials 2018, 179, 265-276, https://doi.org/10.1016/j.conbuildmat.2018.05.227.

75. Bipinbal, P.K.; Kutty, S.K.N. A comparative study of short nylon fiber-Natural rubber composites prepared from dry rubber and latex masterbatch. Journal of Applied Polymer Science 2008, 109, 1484-1491, https://doi.org/10.1002/app.28125.

76. Cen, L.; Lv, G.Z.; Tan, X.W.; Gong, Z.L. Short Nylon Fibers Waste Modified with Glycidyl 3-Pentadecenyl Phenyl Ether to Reinforce Styrene Butadiene Rubber Tread Compounds. Advances in Polymer Technology 2019, 2019, https://doi.org/10.1155/2019/5847292.

77. Kanbargi, N.; Lesser, A.J. Improving adhesion between aramid fibers and natural rubber through morphological and synthetic modification of the fibers. Journal of Applied Polymer Science 2018, 135, https://doi.org/10.1002/app.45520.

78. Ismail, M.N.; Ghoneim, A.M. The effect of the adhesion system on the physico-mechanical and electrical properties of styrene-butadiene rubber/polyester short-fiber composites. Polymer-Plastics Technology and Engineering 1999, 38, 71-86, https://doi.org/10.1080/03602559909351560.

79. Khalil, A.M.; El-Nemr, K.F.; Khalaf, A.I. Effect of short polyethylene terephthalate fibers on properties of ethylene-propylene diene rubber composites. Journal of Polymer Research 2012, 19, 9883, https://doi.org/10.1007/s10965-012-9883-8.

80. Visakh, P.M.; Thomas, S.; Oksman, K.; Mathew, A.P. Crosslinked natural rubber nanocomposites reinforced with cellulose whiskers isolated from bamboo waste: processing and mechanical/thermal properties. Composites Part A: Applied Science and Manufacturing 2012, 43, 735-741, https://doi.org/10.1016/j.compositesa.2011.12.015.

81. Riyajan, S.A.; Intharit, I.; Tangboriboonrat, P. Physical properties of polymer composite: Natural rubber glove waste/polystyrene foam waste/cellulose. Industrial Crops and Products 2012, 36, 376-382, https://doi.org/10.1016/j.indcrop.2011.10.017. 